\title{
Setting the evolutionary timeline: Tillandsia landbeckii in the Chilean Atacama Desert
}

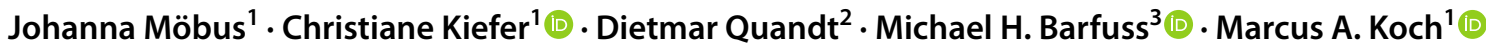

Received: 21 December 2020 / Accepted: 24 April 2021

(c) The Author(s) 2021

\begin{abstract}
The Chilean Atacama Desert is among the oldest deserts of the world. Here, Tillandsia landbeckii is forming a unique vegetation type known as Tillandsia lomas. This vegetation consists in its typical configuration of one single vascular plant species only and forms regular linear structures in a sloped landscape and is largely depending on fog occurrence as dominant source of water supply. Without developing a typical root system, there are only few other terrestrial Tillandsia species growing on bare sand in Chile and Peru such as T. marconae, T. virescens, T. purpureaor T. latifolia. Although phylogenetic evidence is limited, convergent evolution of this unique growth behavior is evident. The predominantly arid and hyper-arid climate exists since the Early Miocene, which raises the question about timing of $T$. landbeckii evolutionary history. Phylogenomic analyses using whole plastome sequence data highlight the onset of diversification in T. landbeckii approximately 500,000 years ago. We also demonstrate subsequent secondary genetic contact with $T$. purpurea during the Late Pleistocene using DNA sequence data and genome size estimates, which resulted into the formation of $T$. marconae.
\end{abstract}

Keywords Atacama desert $\cdot$ Chile $\cdot$ Divergence time $\cdot$ Plastome $\cdot$ Tillandsia landbeckii $\cdot$ Tillandsia lomas

\section{Introduction}

There are some rare ecosystems on earth that demand extreme adaptations from their inhabitants. One of these places is the Atacama Desert. It is known to be the world's oldest and driest non-polar desert, which has been predominantly hyperarid (at least in the core zone) since the Miocene or even longer (Hartley et al. 2005; Ritter et al. 2018). Despite this severe aridity, the Atacama Desert is habitat for specialized plants building local vegetation that can only exist because of unique climatic conditions occurring in this

Handling editor: Martin A. Lysak.

Contribution to "Living at its dry limits - Tillandsiales in the Atacama Desert".

Marcus A. Koch

marcus.koch@cos.uni-heidelberg.de

1 Centre for Organismal Studies, Heidelberg University, 69120 Heidelberg, Germany

2 Nees-Institute for Biodiversity of Plants (NEES), University of Bonn, 53115 Bonn, Germany

3 Department of Botany and Biodiversity Research, University of Vienna, 1030 Vienna, Austria area (Schulz et al. 2012; Bull et al. 2018). The Atacama Desert is stretching along the southern Peruvian and northern Chilean coast with its core zone of hyperaridity between 15 and $30^{\circ} \mathrm{S}$ (Houston and Hartley 2003). The eastward extent of the desert is limited by the Andean Cordillera. It only stretches from 20 to around $100 \mathrm{~km}$ inland (Rundel et al. 2007) with altitudes between sea level and $3500 \mathrm{~m}$ above sea level (m a. s. 1.) (Houston and Hartley 2003). In these arid and hyperarid regions, fog is often the most important source of water for plant life. Fog zones occur mainly in the cliffs close to the coastline above $400 \mathrm{~m}$ and in mountain slopes facing the predominant winds (S and SW) that advect the stratocumulus clouds. Concentrated against the hillsides they allow the development of plant communities, which are called "lomas" (Spanish for small hills) formations or fog oases. The mountainous coast, especially in northern Chile, tends to trap the coastal fog and further enhance the aridity of the continental interior. Only fog corridors connecting the coast with the intermediate depression enable loma formation also in the inland (Alpers and Brimhall 1988; Rundel et al. 1991; Cereceda et al. 2004). The existence of vegetation depends heavily on the altitude and where the top and bases of the stratocumulus clouds occur in the region (Cereceda et al. 2004). 
Frequent members of loma formations are from the family of Bromeliaceae, most commonly known from tropic or subtropic climates, and among Bromeliaceae members of the genus Tillandsia often contribute to loma vegetation. Tillandsia $\mathrm{L}$. is the largest genus within the family of Bromeliaceae and respective subfamily Tillandsioideae. The subfamily is composed by four tribes: Catopsideae, Glomeropitcairnieae, Vrieseeae and Tillandsieae including 22 genera in total and comprising c. 1400 species (Barfuss et al. 2005, 2016; Gomes-da-Silva and Costa 2013; Leme et al. 2017). The more than 600 epiphytic and sometimes terrestrial species of the genus Tillandsia are distributed from southern United States to central Argentina and Chile (Smith and Downs 1977). The genus was traditionally divided into seven subgenera: Allardtia A. Dietr., Anoplophytum (Beer) Baker, Diaphoranthema (Beer) Baker, Phytarrhiza (Vis.) Baker, Pseudalcantarea (Beer) Baker, Pseudo-Catopsis Baker and Tillandsia (Smith and Downs 1977). These subgenera turned out to be mostly non-monophyletic; therefore, a new subdivision was suggested: Aerobia Mez in C.DC., Anoplophytum, Diaphoranthema, Phytarrhiza, Pseudovriesea Barfuss $\&$ W. Till, Viridantha (Espejo) W. Till \& Barfuss, Tillandsia and several unclassified species complexes (Barfuss et al. 2016). Subgenus Allardtia is treated now in synonymy of subgenus Tillandsia, and Pseudalcantarea was elevated to generic rank (Barfuss et al. 2016). Several Tillandsia species invaded sandy soil habitats with adaptations like epiphytic or unrooted (epiarenitic) growth, utilization of crassulaceaen acid metabolism (CAM) and specialized leaves with water absorbing trichomes (Rundel et al. 1997; Zizka et al. 2009). In fact, they possess rudimental roots but without function regarding water uptake or solidification on the surface (Rauh 1985). Terrestrial communities with species from the genus Tillandsia, also called "tillandsiales," are quite abundant in the Atacama Desert but their existence follows a distinct pattern and is associated to the occurrence of above-mentioned fog corridors (Pinto et al. 2006). In Chile tillandsiales are distributed in altitudes from 900 to $1200 \mathrm{~m}$ in a linear area of $470 \mathrm{~km}$ from Arica $\left(18^{\circ} 20^{\prime} \mathrm{S}\right)$ to the Loa River $\left(21^{\circ} 25^{\prime} \mathrm{S}\right)$ with a large gap from Camarones $\left(19^{\circ} 15^{\prime} \mathrm{S}\right)$ to Iquique $\left(20^{\circ} 12^{\prime} \mathrm{S}\right)$. Furthermore, they can be found in ranges from 3 to $45 \mathrm{~km}$ inland. Lomas show different level of degradation according to their geographic position. They prosper well in belts near the coast growing on slopes toward SW and $\mathrm{W}$ and become sparse toward inland localities. They also show evidence of dieback in their lower limits showing the struggle and dependence of atmospheric moisture (Cereceda et al. 2004; Pinto et al. 2006; Schulz et al. 2011). Pinto et al. (2006) recorded three different terrestrial Tillandsia species in northern Chile: Tillandsia landbeckii Phil., Tillandsia marconae W.Till \& Vitek and Tillandsia virescens Ruiz Pav. Tillandsia marconae only occurs close to Arica and $T$. virescens is found in small patches only with close proximity to T. landbeckii lomas. Most fog oases observed by Pinto et al. (2006) were monospecific stands of T. landbeckii (Koch et al. 2019, 2020), which is the main object of this study. Tillandsia landbeckii belongs to the subgenus Diaphoranthema, which may include a total of 29 species (Donadío et al 2015; but see also Barfuss et al. 2016). They are characterized by few (1-10) reduced flowers and grow on trees, bushes, rocks or bare sand in altitudes from sea level to $4300 \mathrm{~m}$ (Donadío et al. 2015). Some species within the subgenus Diaphoranthema are facultatively autogamous or even cleistogamous, which makes them independent from pollinators (Till 1992). This seems to be advantageous, considering the extreme habitat with possibly rare occurrence of potential pollinators as shown for T. landbeckii (Koch et al. 2019).

Drastic environmental changes from wet and cold to dry and warm periods within Pleistocene glacial-interglacial cycles might have been a strong impulse for population divergence, species distribution and speciation by influencing gene flow, demographic expansion or contraction and genetic bottlenecks. Unfortunately, there are only very few studies about how these fluctuations in climatic conditions during the Quaternary impacted plant species and especially loma formations in the Atacama Desert. Gilmartin (1983) for example hypothesized that there was a rapid speciation of xeromorphic groups of Tillandsia during the Pleistocene. However, since hyperarid conditions exist for much longer at this area, it seems to be possible that some of the adapted species are much older, as well. According to Granados Mendoza et al. (2017) migration of members of the subgenus Diaphoranthema, which includes T. landbeckii, might have started from the Andes and Southern Chile toward the Brazilian shield. Furthermore, the origin of the lomas in Peru show subtropical connections, while the flora of the Chilean lomas show more affinities to the flora of Central Chile and the adjacent Andes. In Peru, the most widely distributed loma forming Tillandsia species is T. purpurea Ruiz Pavon, and in the respective contact zone with $T$. landbeckii, $T$. marconae has been found (Zizka and Munoz-Schick 1993). There is convincing evidence that T. marconae is a hybrid between both species, T. landbeckii and T. purpurea (Bratzel et al. 2020). This coincides with the assumption of a strong phytogeographic boundary existing between Peru and Chile (Rundel et al. 1991, 2007) and independent evolutionary histories of the various species can be hypothesized since $T$. purpurea has been placed in subgenus Phytarrhiza, which also appeared to be a polyphyletic subgenus (Barfuss et al. 2016). Among tribe Tillandsieae terrestrial growth forms have evolved on species-group/clade-level at least five times independently (Barfuss et al. 2016).

Herein we present a time calibrated subfamily-wide plastome phylogeny demonstrating stem and crown group age of Tillandsia landbeckii. Since T. marconae has been 
identified as a hybrid between T. purpurea and T. landbeckii, we also tested the hypothesis that as a consequence $T$. marconae plastome transmission and/or plastome capture must be younger than the crown group age of $T$. landbeckii. The onset of T. marconae evolutionary history might denote a major environmental change shifting distribution areas of Peruvian T. purpurea lomas southward and Chilean T. landbeckii lomas northward and consequently resulting in a sympatric narrow distribution range.

\section{Material and methods}

\section{Study design}

There is limited information on divergence time estimates and calibration points in Bromeliaceae in general and subfamily Tillandsioideae in particular. The most comprehensive study has been presented by Givnish et al. (2011). From this study, we selected a set of taxa representing crucial nodes being used as calibration points in our analysis. Previous taxonomic and phylogenetic results and conclusions are almost exclusively based on plastid DNA information; therefore, we expanded earlier few gene analyses (Givnish et al. 2011; Barfuss et al. 2016) to a whole plastome analysis. The respective largely expanded amount of DNA sequence information can then be used to resolve also divergence time estimate for shorter periods in time of few thousands or hundred-thousands of years (e.g., Hohmann and Koch 2017; Hohmann et al. 2018) and, thereby, resolving also node ages of herein investigated $T$. landbeckii.

\section{Plant material}

Taxon sampling from Bromeliaceae is representing subfamily Tillandsioideae and representatives from its sister clade (selected taxa from subfamilies Pitcairniodeae, Bromeliodieae, Puyoideae and Hechtioideae) (Online Resource 1). We also selected a representative Tillandsia landbeckii accession from Chilean terrestrial loma vegetation and Peruvian accessions from higher altitudes (T. landbeckii ssp. andina - MHJB-B1687/HEID113097, $2300 \mathrm{~m}$ a. s. 1.; T. landbeckii var. rigidior - MHJB-B1684/HEID113094, $3100 \mathrm{~m}$ a. s. 1.) allowing to include the species' geographic, ecological and climatic disjunction (Peru versus Chile). Furthermore, two accessions from T. purpurea and T. marconae have been investigated, because $T$. marconae was proposed hybrid between $T$. purpurea and T. landbeckii with a very restricted intervening distribution range. Two of these accessions (T. purpurea - P06, and T. marconae - P07) are growing sympatrically in the same loma vegetation near Tocyasca, Peru. The other two accessions are also from Peru (T. purpurea: HEID104854/Rauh38703; T. marconae: HEID103591/Rauh20899). Plants are cultivated at Heidelberg Botanical Garden as permanent living collections (HEID). This selection of accessions allows testing some key hypotheses on the timeline of evolutionary history of T. landbeckii in Peru and Chile.

For genome size estimates we used 15 accessions grown at Heidelberg Botanical Garden representing 3 species ( $T$. landbeckii, T. marconae, T. purpurea) (Online Resource 1).

Two additional plastomes were selected from NCBI representing T. usneoides (KY293680) and Ananas comosus (AP014632 [= NC026220]) with detailed information on its respective structure and function (Poczai and Hyvönen 2017; Nashima et al. 2015). Additional plastomes from Ochagavia carnea (NC045386), Puya mirabilis (NC045380), and Fasciluaria bicolor (MN563795) (Paule et al. 2020a, b) have been used for further comparisons of gene content and selected sequence characteristics.

\section{DNA extraction, plastome sequencing, assembly and high-quality reference plastomes}

DNA was extracted from fresh leaf material of all samples using the Invisorb Spin Plant Mini Kit (STRATEC Biomedical, Birkenfeld, Germany) following the manufacturer's protocol or using a modified CTAB protocol optimized for Bromeliaceae (Bratzel et al. 2020). DNA integrity was checked on 1\% agarose gels and DNA concentration was measured using the Invitrogen Qubit 2.0 fluorometer kit (Thermo Fischer, Freiburg, Germany). Preparation and sequencing of total genomic DNA libraries were performed at the CellNetworks Deep Sequencing Core Facility (Heidelberg, Germany). Library insert size was between 200 to $400 \mathrm{bp}$ and the SMARTer ${ }^{\circledR}$ ThruPLEX $^{\circledR}$ Tag-seq kit (Takara Bio Inc, Saint-Germain-en-Laye, France) was used for library preparation. Sequencing was performed on an Illumina NextSeq 550 sequencing system in 150-bp paired-end mode. Raw Illumina reads were filtered for quality by retaining only reads with a Phred score $>30$ and longer than $50 \mathrm{bp}$ and adapter sequences were removed both by using the program trimmomatic (Bolger et al. 2014). For further analyses, only reads were used where both paired reads passed the filtering criteria. For generating reference-based assemblies, the trimmed reads were mapped to an earlier published $T$. usneoides plastid genome (KY293680) using BWA (mem algorithm; Li 2013) setting the penalty for unpaired reads to 15 . Prior to mapping one of the copies of the inverted repeat region was removed from the reference sequence as duplicate sequences in the reference produce secondary alignments. To increase mapping quality further, the mappings were filtered for reads with a mapping quality $>1$ and duplicate reads were removed both using samtools (Li et al. 2009). Gatk3 tools (McKenna et al. 2010) were used for enhancing alignment quality in case of presence 
of indels and for variant calling (SNP as well as indel polymorphisms). The gatk3 tool FastaAlternateReferenceMaker was used for generating sequences including the detected SNPs and indels and regions with a coverage $<5$ and a mapping quality $<30$ were masked using samtools maskfasta (Li et al. 2009). All plastid sequences obtained from the reference-based mapping approach were aligned to the reference sequence and 120 gene annotations were transferred using the program Geneious (version 7.1.7, Biomatters Ltd., Auckland, New Zealand). Coding regions as well as regions encoding tRNAs or rDNAs were extracted using bedtools (Quinlan and Hall 2010) except for $y c f l$ with sequence overlapping with inverted repeat and aligned using mafft (Katoh et al. 2002). All resulting 112 gene alignments were then concatenated using the script catfasta2phyml (https://github. com/nylander/catfasta2phyml). The alignment generated from 112 coding sequences of the plastid genome (including rDNA and tRNA encoding sequences) had a total length of $71,429 \mathrm{bp}$ and was used for phylogenetic reconstruction and divergence time estimates (see below; DRYAD submission https://doi.org/10.5061/dryad.kh189324d).

In addition to the reference-based approach Unicycler v0.4.8 (Wick et al. 2017) was used for generating de novo assemblies of four accessions (T. usneoides (HEID109235), T. purpurea (HEID104854), T. espinosae (HEID130781), and T. malzinei (HEID108286)). The de novo assemblies were indexed as blast libraries and searched for contigs matching the plastid genome by using T. usneoides complete plastome (NCBI KY293680) as query sequence. By aligning the matching contigs to the query sequence order and orientation of contigs were determined, and primers were designed for amplifying regions between contigs. PCR products were Sanger sequenced and used for filling gaps between contig ends. Detailed primer information and PCR protocols are provided with Online Resource 2.

\section{Phylogenetic analysis and divergence time estimates}

In order to determine the most suitable molecular evolutionary model as well as partitioning schemes for phylogenetic reconstruction PartitionFinder 2.1.1 (Lanfear et al. 2017) was used. All models implemented in RAxML-ng (Kozlov et al. 2019) as well as all models implemented in BEAST2 (Bouckaert et al. 2014) were tested using the corrected Akaike Information Criterion (AICc) for model selection in a greedy search, and branch lengths were allowed to be linked. RAxML-ng (Kozlov et al. 2019) was used for phylogenetic reconstruction taking the alignment described before as well as the list of partitions and according most suitable models as input. Calculations started from 20 parsimony trees generated by the program, branch length was set to linked and 1000 bootstrap replicated were run.
The resulting tree with added bootstrap support values was visualized using the program FigTree v1.4.2 (Rambaut and Drummond 2012).

Divergence times estimates were performed using the program BEAST2 (Bouckaert et al. 2014) using the alignment as well as the partition scheme and according models described above and in the previous section and trees and clock models were linked. In respect to the best-fitting models K81 had to be excluded as BEAST2 cannot handle those models. In the six cases where K81 had been determined by PartitionFinder 2.1.1 as best-fitting model the second best model was chosen instead (subset 4: TIM $+\mathrm{I}$, subset 7: $\mathrm{TIM}+\mathrm{I}+\mathrm{G}$, subset 12 : TIM, subset $15: \mathrm{TVM}+\mathrm{I}$, subset 18: TIM and subset 33: K80). A relaxed log normal molecular clock was applied allowing for rate heterogeneity across branches, the tree resulting from the RAxML-ng analysis was used as starting tree and the Birth Death model was set as prior for all partitions. Secondary divergence time estimates were constrained using estimates from a plastid 8-locus dataset (Givnish et al. 2011): (A) crown group age of subfamiliy Tillandsioideae (T. usneoides versus Catopsis floribunda; split time 14 mya with a SD of \pm 0.5 mya); (B) crown group age of Puyoideae being a member of the sister group of subfamily Tillandsioideae (Puya laxa versus $P$. alpestris; split time 9.8 mya with a SD of \pm 0.7 mya). The Markov Chain Monte Carlo (MCMC) algorithm was run for 100 million generations and every $1000^{\text {th }}$ tree was sampled, and six independent runs using identical settings were performed. Tracer v1.7.1 (Rambaut et al. 2018) was used for determining whether the stationary phase was approached, whether the effective sampling size was $>200$ and whether all runs had converged. Using LogCombiner v2.5.1 trees from all 6 runs were combined and $20 \%$ of the data were excluded as burnin. TreeAnnotator v2.5.1 was used for adding age estimates as Median heights to the nodes before visualizing the tree by FigTree v1.4.2. The tree is provided with DRYAD (https://doi.org/10.5061/dryad.kh189324d).

\section{DNA barcoding of Tillandsia purpurea and $T$. marconae}

The herein selected accessions of Tillandsia, and in particular T. purpurea and T. marconae, have been also used to analyze their phylogenetic position in a genus-wide phylogeny of Tillandsia and subfamily Tillandsioideae presented by Barfuss et al. (2016). In this earlier study, a preliminary analysis of plastid trnK-matK-trnK (Large Single-Copy region) (alignment length of $1887 \mathrm{bp}$.), rpoBtrnC-pet $\mathrm{N}$ (LSC-Region) (alignment length of $3225 \mathrm{bp}$.) and $y c f 1$ (Small Single-Copy Region) (alignment length of 4722 bp.) provides a comprehensive phylogenetic overview, and it was indicated that $T$. purpurea represents a species complex. However, they did not include T. marconae, which 
our research group has shown earlier to be of a putative hybrid origin (Bratzel et al. 2020). We extracted the respective marker regions from our data and re-run the large-scale phylogenetic tree (Barfuss et al. 2016) including our herein analyzed Tillandsia accessions using RaxML-ng with the following settings: raxml-ng —all —msa - brlen linked model GTR - tree pars $\{20\}$-bs-trees 200 (Kozlov et al. 2019).

\section{Genome size estimates}

Genome size estimates were performed for selected individuals to analyze potential ploidal level variation among the three species T. purpurea, T. landbeckii and T. marconae to collect further information on hybrid speciation processes (e.g., homoploid hybrid speciation). Nuclear DNA content was determined using flow cytometry following a simplified protocol (Doležel et al. 2007). Approximately, $10 \mathrm{~mm}^{2}$ of fresh and young leaf tissue from each plant to be analyzed was chopped together with an appropriate volume of respective internal reference standards (Raphanultas sativus cv. Saxa, 1.11 pg/2C; Solanum lycopersicum cv. Stupicke, 1.96 pg/2C; Zea mays cv. CE-777, 5.43 pg/2C) (Doležel et al. 1992) using a sharp razor blade in a Petri dish containing $0.5 \mathrm{~mL}$ of ice-cold Lysis buffer LB01 (Doležel et al. 1989) supplemented with $2 \mu \mathrm{g} \mathrm{mL}-1 \beta$-mercaptoethanol. The suspension was filtered through a $30-\mu \mathrm{m}$ CellTrics ${ }^{\circledR}$ filter (Sysmec-Partec GmbH, Münster/Görlitz, Germany) and $1.5 \mathrm{~mL}$ of LB01 buffer was added as well as propidium iodide and RNase (both to a final concentration of $50 \mu \mathrm{g} \mathrm{mL}-1$ ). After $90 \mathrm{~min}$ incubation on ice, the relative fluorescence intensity of 5000 particles was recorded using a flow cytometer (CyFlow Space; Sysmex-Partec GmbH, Münster/Görlitz, Germany) equipped with a green (532-nm) solid state laser. We applied the following stringent criteria to get precise and stable flow cytometric results: (i) only analyses where the coefficient of variation of the sample peak was below 5\% were taken into account, (ii) each sample was measured twice on different days to minimize potential random instrumental drift (Doležel and Bartoš 2005), and (iii) if the between-day variation exceeded a 5\% threshold another measurement was made and the most remote value was discarded when the sample was re-analyzed. The histograms were evaluated with the FloMax FCS 2.0 program (Sysmex-Partec GmbH, Münster/Görlitz, Germany).

\section{Results and discussion}

\section{Bromeliaceae high-quality reference genomes}

Bromeliad phylogenetics and evolutionary research is largely relying on plastid markers, therefore there is some need of respective reference plastomes. Complete chloroplast genomes from the family of Bromeliaceae are published for six species only (Ananas comosus-AP014632, KR336549, KU598872; Tillandsia usneoides-KY293680; Ochagavia carnea-MN563799; Ochagavia elegans - MN563796 and MN563798; Puya mirabilis-MN563797; Fascicularia bicolor ssp. bicolor-MN563795), and only one represents the genus Tillandsia. Only the plastomes of Ananas (Nashima et al. 2015; Redwan et al. 2015) and Tillandsia usneoides (Poczai and Hyvönen 2017) have been discussed in detail, the other GenBank submissions remained largely unexplored in earlier studies (Liu et al. 2016; Paule et al. 2020a, b).

Within this study four additional plastomes representing four Tillandsia species (T. usneoides, T. malzinei, T. purpurea, T. espinosae) were de novo assembled from genome skimming data nearly doubling the number of available plastome data. Herein, newly presented plastomes had an average size of $157,163 \pm 847 \mathrm{bp}$ (Online Resource 3), and their structure was the same quadripartite structure as in already published plastid genomes [Large Single-Copy region (LSC) neighboured by Inverted repeat b (IRb), followed by Small Single Copy region (SSC) and Inverted Repeat a (IRa); length of segments is shown in Table 1) (Gitzendanner et al. 2018). The two inverted repeat regions were identical so they assembled into one contig, which was inserted as IRa into the scaffolded plastomes, and connections between contigs as well as short sequences between contigs were confirmed and added by Sanger sequencing. This led to slight size differences between IRa and IRb (3 to $266 \mathrm{bp}$ ). In all four plastomes, 94 genes could be annotated in LSC and SSC (72 protein coding, 22 tRNAs, 0 rRNAs) and 20 genes in the IRa/IRb regions ( 8 protein coding (including $y c f 15$ ), 8 tRNAs, 4 rRNAs) making up a total of 134 genes (gene list is found with DRYAD submission https://doi.org/10.5061/dryad. kh189324d). However, two of these genes were found to be partially deleted in two accessions: In T. usneoides $106 \mathrm{bp}$ were missing from rpl23 (usually $174 \mathrm{bp}$ full length) and in $T$. purpurea $23 \mathrm{bp}$ were missing from psaI (usually $111 \mathrm{bp}$ full length). In addition, $y c f 1$ is located in all four

Table 1 Total length and region lengths (in basepairs) of herein presented reference plastomes including large single copy (LSC), small single copy (SSC) and inverted repeat (IR) regions a and b

\begin{tabular}{lllll}
\hline Plastome & T. usneoides & T. malzinei & T. purpurea & T. espinosae \\
\hline $\begin{array}{l}\text { Total length } \\
\text { (bp) }\end{array}$ & 155,949 & 157,774 & 156,816 & 158,114 \\
LSC (bp) & 85,389 & 86,021 & 85,414 & 86,338 \\
SSC (bp) & 17,853 & 18,293 & 17,949 & 18,339 \\
IRa (bp) & 26,716 & 26,723 & 26,720 & 26,712 \\
IRb (bp) & 25,978 & 26,724 & 26,720 & 26,712 \\
\hline
\end{tabular}


generated plastomes on the border of SSC and IRa and creates a pseudogene of roughly $1000 \mathrm{bp}$ (1089 bp in $T$. purpurea and T. espinosae, $1077 \mathrm{bp}$ in T. malzinei and $1091 \mathrm{bp}$ in T. usneoides). The partial duplication is due to the IR expansion (Poczai and Hyvönen 2017). Hence, difference in plastome size of T. usneoides of KY293680 compared to our herein presented data of $2.4 \%$ are largely because of $r p l 32$ and $y c f 1$ (pseudogene) sequence information not present in our accession. Furthermore, more than $1000 \mathrm{bps}$ (position 6000-7100 spacing rps 16 and trnQ) have not been found in our accession of T. usneoides, but BLAST searches demonstrate that this sequence information is distributed with very high sequence identity in the Ananas comosus nuclear genome (chromosomes 1, 2 and 7). However, this may be validated in future studies, e.g., via long-read sequencing approaches or fragment-specific and individual PCR-based tests relying on unique primer combinations.

Both, the already published plastomes and the ones generated in this study contain overall the same set of genes, with the exception of $y c f 15$, which has been only described for the published T. usneoides plastome (Poczai and Hyvönen 2017) as well as the four Tillandsia plastomes generated in this study. Despite this, we were able to find the sequence of 256 bp in Ananas comosus, Puya mirabilis, Ochagavia carnea and Fascicularia bicolor ssp. bicolor, as well. This was verified with a BLAST search against Arabidopsis thaliana. This gene is considered to be a pseudogene (Poczai and Hyvönen 2017).

In comparison to already published plastid genomes we identified 134 genes in our newly assembled plastids. This means there is a minor discrepancy in gene content of four genes to Ochagavia carnea and to Puya mirabilis and 1 gene to Fascicularia bicolor subsp. bicolor (Table 2). Order of genes and annotations among studied plastomes are identical (gene list provided with DRYAD submission https://doi.org/10.5061/dryad.kh189324d). Accession codes for raw sequence reads are provided with Online
Resource 1 and can be found with NCBI under BioProject ID PRJNA701548.

\section{Phylogenetic reconstructions are congruent with traditional concepts}

The results from maximum likelihood analysis of the plastome data (Fig. 1) are congruent with recent phylogenetic analyses of the Bromeliaceae in general and subfamily Tillandsiodeae in particular (e.g., Givnish et al. 2011; Barfuss et al. 2016).

Bootstrap support in our analysis is most often very high. In case of Puya laxa (Puyoideae) we obtained a similar result as Givnish et al. (2011) demonstrating in ML analysis an unresolved subfamily Puyoideae with deeply branching Puya taxa (bootstrap support for paraphyly 51\%). BEAST analysis (Fig. 2) recovered the same phylogenetic topology and, thereby, confirming a robust phylogenetic signal of the dataset. Tillandsia marconae, which is of hybrid origin (Bratzel et al. 2020), appears at two different positions in the phylogenetic tree indicating a putative multiple and polytopic origin. The T. purpurea accession grouped together with one T. marconae and all T. landbeckii accessions might have captured its plastome via reticulate evolutionary processes. The second T. marconae accession (HEID103591/ Rauh20899) has been analyzed earlier in a broader context of the evolution of CAM metabolism in Bromeliaceae (Hermida-Carrera et al. 2020). For this taxon and respective accession CAM metabolisms has been confirmed and maternal phylogenetic affinity with $T$. purpurea has been documented sequencing the $r b c \mathrm{~L}$ gene (Hermida-Carrera et al. 2020). Our second herein analyzed T. purpurea accession (HEID104854) unexpectedly did not group with this $T$. marconae (Fig. 1). However, in an earlier barcoding study using the nuclear gene agt 1 this accession clearly shows a signature of the T. purpurea agt 1 gene (Bratzel et al. 2020). This leads to the conclusion that this T. purpurea accession might be also of hybrid origin or have been affected

Table 2 Comparison of major features among plastomes from bromeliad species deposited with GenBank

\begin{tabular}{llllll}
\hline Plastome & Ananas comosus & $\begin{array}{l}\text { Tillandsia usne- } \\
\text { oides }\end{array}$ & Ochagavia carnea & $\begin{array}{c}\text { Puya mirabilis } \\
\text { Fascicularia } \\
\text { bicolor } \text { subsp. } \\
\text { bicolor }\end{array}$ \\
\hline GenBank code & AP014632 & KY293680 & MN563799 & MN563797 & MN563795 \\
Total length (bp) & 159,636 & 159,657 & 162,835 & 159,829 & 161,423 \\
LSC (bp) & 87,466 & 87,439 & 83,885 & 87,800 & 85,373 \\
SSC (bp) & 18,622 & 18,612 & 18,458 & 18,529 & 18,450 \\
IRa (bp) & 26,774 & 26,803 & 30,246 & 26,750 & 28,800 \\
IRb (bp) & 26,774 & 26,803 & 30,246 & 26,750 & 28,800 \\
Total no. of genes & $134 *(*$ including $y c f 15)$ & 134 & 138 & 130 & 135 \\
No. of genes duplicated & $20 *$ & 20 & 25 & 20 & 22 \\
in the IR & & & & & \\
\hline
\end{tabular}




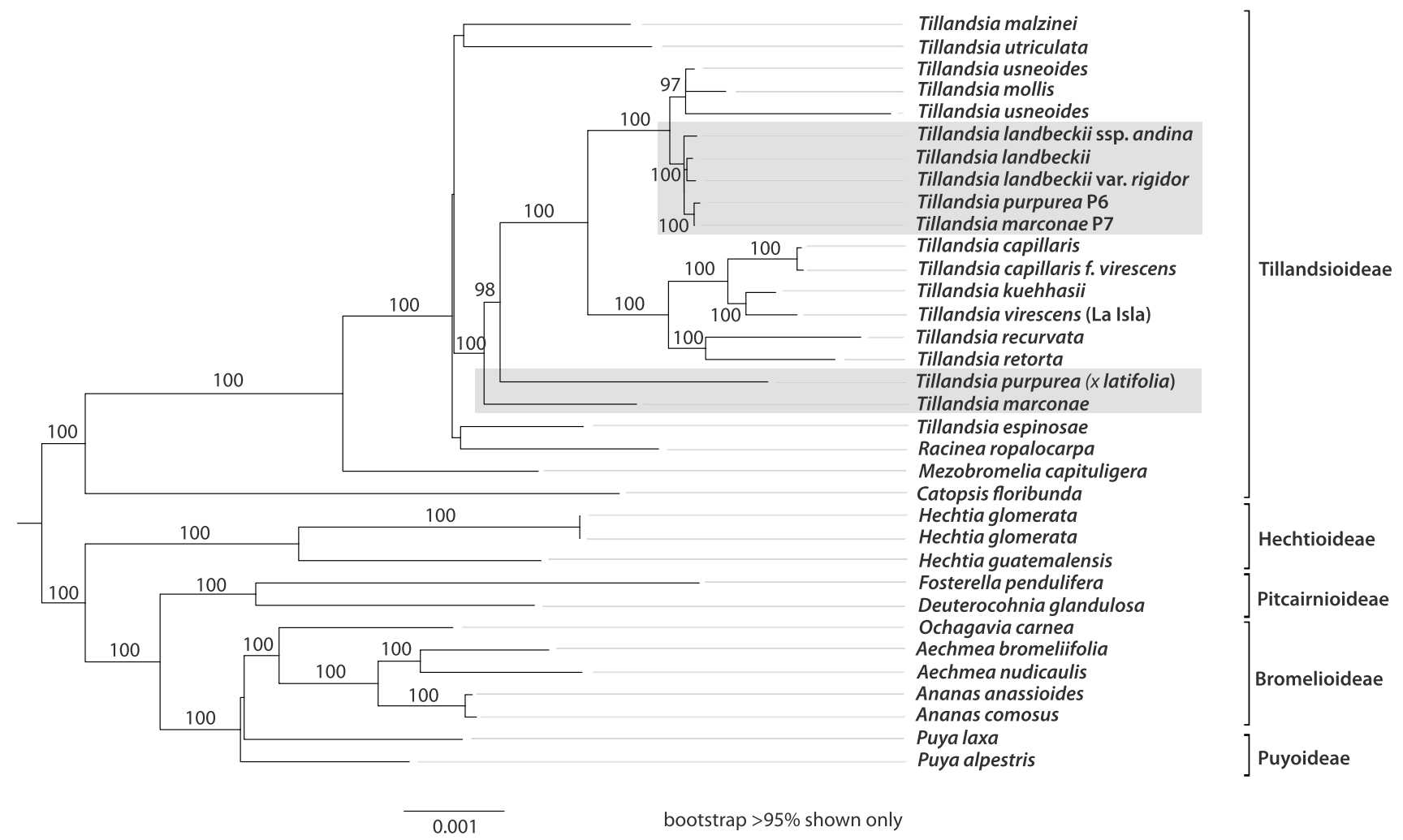

Fig. 1 Maximum likelihood-based phylogeny of plastome coding regions. Bootstrap support is indicated for values $>95 \%$. Tillandsia species in focus of this study are marked with gray boxes (T. land-

by introgression and/or plastid capture of an unknown species. And indeed, Werner Rauh, who collected the plants in 1975 (http://scriptorium.cos.uni-heidelberg.de/entry/? 20233; Koch et al. 2013) added a notice, that it is an unusual "microform" (see next paragraph).

\section{DNA barcoding indicates a putative reticulate origin of Tillandsia marconae}

Maximum-likelihood analysis of herein investigated Tillandsia accessions integrated into the large-scale phylogeny provided by Barfuss et al. (2016) should have guided us to an explanation for the phylogenetic positions of T. marconae and $T$. purpurea. The ML phylogeny is shown in Online Resource 4. This analysis provided some valuable information on $T$. purpurea (HEID104854). This accession has been also recollected later in 1986 by W. Till (Vienna, coll. WT2144) and was named as dwarf form of T. kunthiana Gaudich. (T. latifolia group) with similar plants resembling true $T$. purpurea found nearby (W. Till, coll. WT2146). Therefore, we are confident that the accession analyzed herein is a result of hybridization processes between the two species T. purpurea and T. latifolia, both of them are well-known to build up Peruvian tillandsia lomas (Aponte and Flores 2013; Hesse 2012, 2014; Rundel beckii, T. purpurea, T. marconae). The tree is rooting according to Givnish et al. (2011) and Barfuss et al. (2016), and distance scale represents mean expected rate of substitutions per site

and Dillon 1998). Sympatric occurrence of the various terrestrial Tillandsia has not been documented in a systematic way yet. Fortunately, there is few documentation as illustrated with Fig. 3. In Peru there is T. latifolia growing sympatrically with $T$. purpurea and T. paleacea (Fig. 3b). In Chile near Iquique (Cerro La Isla) there are few $T$. virescens individuals at the top of the hill growing sympatrically with $T$. landbeckii (Fig. 3a). The study site at Tocyasca (Peru) analyzed herein has sympatrically T. purpurea and T. marconae growing and near Ancon (Peru) there is sympatrically growing $T$. landbeckii and T. purpurea (Fig. 3c). Another recent survey of various locations near Tacna (Peru) exemplified sympatric occurrence of T. purpurea, T. landbeckii and T. werdermannii Harms in various combinations (Lazo Ramos 2011). In summary this may provide evidence that all these seven terrestrial and on sand growing (epiarenic) Tillandsia species from Chile and Peru may have genetic contact among each other.

\section{Genome size estimates indicate homoploid and reticulate evolution among Tillandsia landbeckii and $T$. purpurea}

Estimated genome sizes for the three species T. landbeckii, T. purpurea and T. marconae are provided with Suppl. 


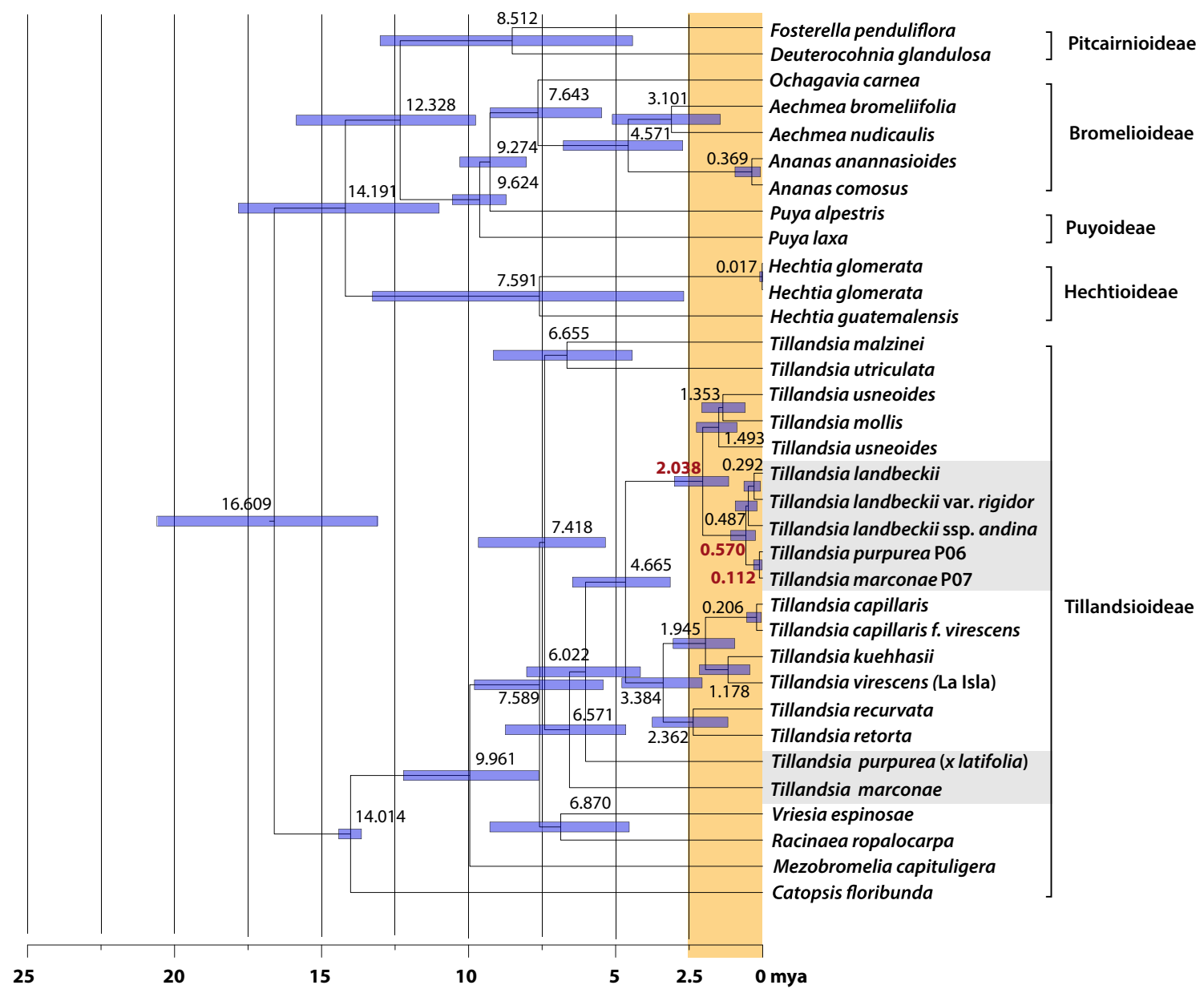

Fig. 2 BEAST chronogram with divergence time estimates indicated (blue bars represent 95\% confidence interval). Tillandsia species in focus of this study are marked with gray boxes ( $T$. landbeckii, $T$. purpurea, T. marconae). Divergence time estimates relevant to our understanding of $T$. landbeckii evolutionary history are indicated in red
Mat. Table 1. For T. landbeckii genome sizes vary from 2.23-2.61 pg $(\mathrm{n}=10$, mean $2.41 \mathrm{pg}, \mathrm{SD} 0.11), T$. purpurea varies from 2.11-2.96 pg $(\mathrm{n}=3$, mean $2.40 \mathrm{pg}$, SD 0.39), and T. marconae showed a mean of $2.28 \mathrm{pg}(\mathrm{n}=2$, SD 0.01 ). We found no difference among measurements from runs with different standards, and here we present the values referring to the Raphanus standard. Individual chromosome counts of these accessions are not available. However, for T. purpurea a haploid chromosome number $(\mathrm{n}=\mathrm{x}=25)$ has been reported (Brown and Gilmartin 1989), confirming the predominant number of $2 \mathrm{n}=2 \mathrm{x}=50$ found within Bromeliaceae (e.g., Cotias de Oliveira et al. 2000; Paule et al. 2020a, b). These results allow us to assume that all three species are on the same ploidal level. Considering that two analyzed $T$. purpurea and T. marconae accessions from the same loma vegetation carry a $T$. landbeckii plastome type, it can be hypothesized that not only $T$. marconae evolved with varying parental contribution (maternal contribution from $T$. landbeckii and T. purpurea), but also T. purpurea is subjected to reticulate evolutionary processes and thereby capturing $T$. landbeckii plastomes, which is best explained by additional (back)crossing events toward T. purpurea.

Since herein investigated $T$. purpurea from Tocyasca (Peru) shows genetic contact with $T$. latifolia, and since also genetic contact among the other epiarenic species is likely, we hypothesize a common diploid base chromosome number of $2 n=50$ among all these species not hindering respective gene flow (Paule et al. 2020a, b).

\section{BEAST analysis indicates Pleistocene crown ages of Tillandsia landbeckii evolutionary history}

Divergence time estimates (crown and stem group ages) among the five selected subfamilies do not differ between our study and Givnish et al. (2011) (Fig. 2, Table 3).

This has to be expected, because we used divergence times from this study to calibrate our phylogeny. However, it demonstrates the robustness of the datasets, and it further 

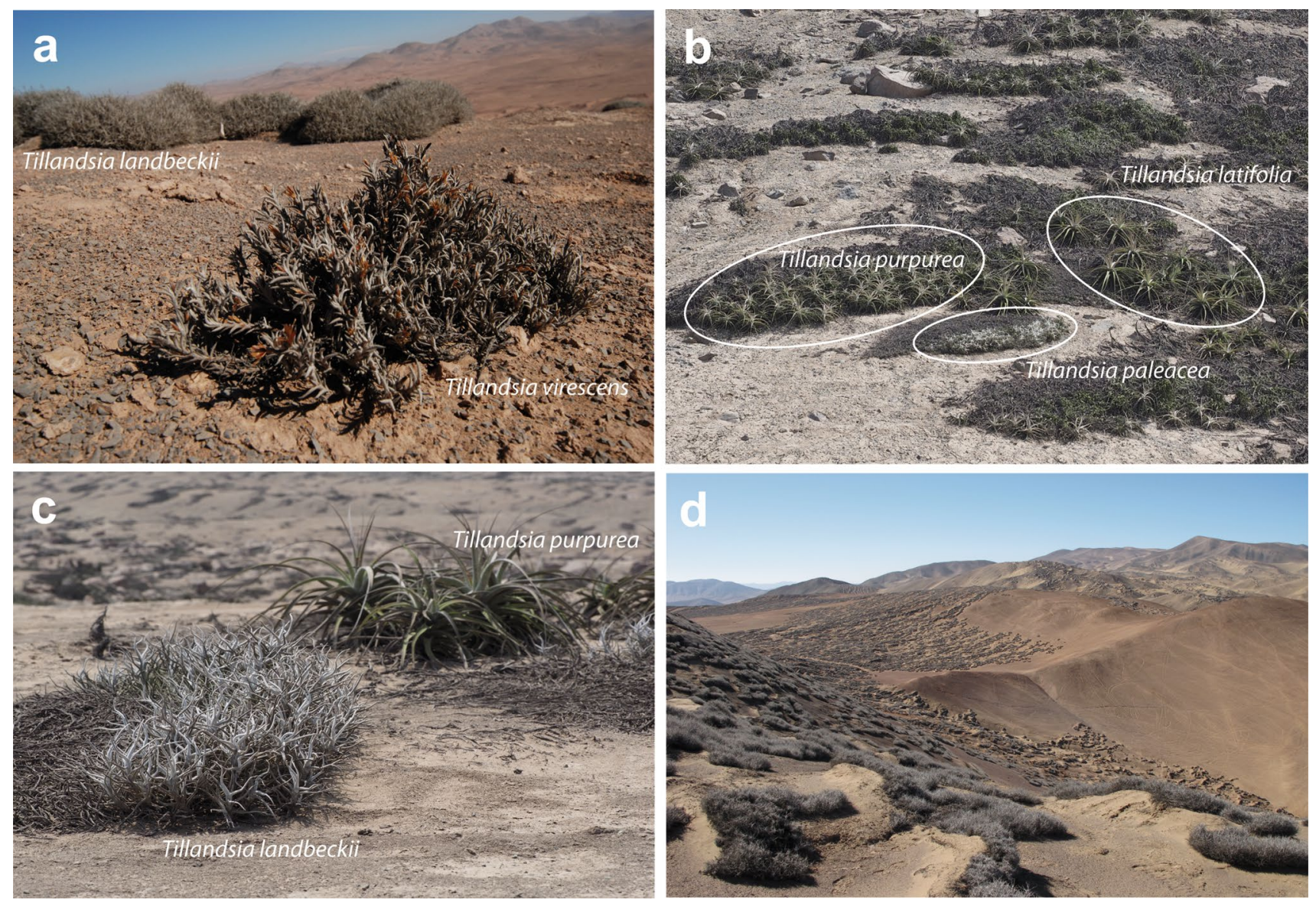

Fig. 3 a Sympatrically growing Tillandsia virescens and T. landbeckii (background) close to Iquique (Cerro La Isla, Chile) (image taken by M. Koch, Nov 2016). b Sympatrically growing T. latifolia, T. purpurea and T. paleacea at Reserva Nacional de Ancon (Peru) (image taken by M. Douglas, 9 Dec 2017). c Sympatrically growing $T$. land-

beckii and T. purpurea $15 \mathrm{~km} \mathrm{NE}$ of Ancon (Peru) (image taken by M. Douglas, 9 Dec 2017). d Monospecific Loma vegetation of $T$. landbeckii at Cerro Guanacos (Iquique, Chile) (image taken by $\mathrm{M}$. Koch, 22 Nov 2016)
Table 3 Crown and stem group ages of subfamilies included in the chronogram

\begin{tabular}{llllll}
\hline Subfamily/species & \multicolumn{2}{l}{ Stem age (mya) } & & \multicolumn{2}{l}{ Crown age (mya) } \\
\cline { 2 - 3 } & 8 8-locus plastid & Present study & & 8 -locus plastid & Present study \\
\hline Pitcairnioideae & 13.4 & $12.3(9.8-15.9)$ & & 11.8 & $8.5(4.4-13)$ \\
Bromelioideae & 10.1 & $9.3(8-10.3)$ & & 8.9 & $7.6(5.5-9.3)$ \\
Puyoideae & 10.1 & $9.6(8.7-10.6)$ & & 10 & \\
Hechtioideae & 15.2 & $14.2(11-17.8)$ & & 10.3 & $7.6(2.7-13.3)$ \\
Tillandsioideae & 15.4 & $16.6(13.7-21.3)$ & & 14.2 & $14(13.6-14.4)$ \\
T. landbeckii & & $2.038(1.2-3)$ & & $0.57(0.3-1.1)$ \\
T. marconae & & min. age 0.119 & & \\
\hline
\end{tabular}

In brackets, the $95 \%$ probability density for the present study 8-locus plastid estimates are from Givnish et al. (2011) allows to consider our herein presented divergence time estimates for T. landbeckii with confidence. Considering T. mollis and T. usneoides as closest relatives of T. landbeckii (Barfuss et al. 2016) stem and crown group ages of T. landbeckii are 2.038 and 0.570 mya, respectively. This takes into consideration that T. purpurea and T. marconae from the same clade (here growing in the same Tillandsia field) carries respective $T$. landbeckii plastome types transmissed maternally from $T$. landbeckii into these species. Accordingly, the origin of hybrid T. marconae indicating 
past genetic contact between Chilean T. landbeckii and Peruvian $T$. purpurea is estimated with a minimum of 0.112 mya (Fig. 3). This fits well with a rainy northern Atacama Desert in Peru during the last Interglacial (appr. 125 kya) (Contreras et al. 2010), which may have enforced Peruvian T. purpurea to migrate southward and hybridized with $T$. landbeckii. The onset of genetic differentiation in T. landbeckii (crown group age) 0.570 mya is not coinciding with any obvious documented environmental/bioclimatic impact in the Chilean Atacama Desert and, therefore, a trigger of diversification remains unknown

It is remarkable that within subgenus Diaphoranthema (mostly epiphytic species) $T$. landbeckii belongs to a clade of few Tillandsia species comprising mostly epiarenic or epilithic species, with epiarenic species being quite rare in the genus (Suppl. Material Fig. 1). This supports the view that epiarenic life form is ancestral to this clade, which originated in the early Pliocene appr. 4.67 mya. In the Atacama Desert a semiarid climate persisted from 8 to 3 mya, punctuated by a phase of increased aridity at ca. 6 mya (Hartley and Chong 2002). Therefore, onset of the evolution of this particular clade might have followed this punctuated phase. The stem group age of $T$. landbeckii coincides with the onset of the ENSO climate system (Hartley and Chong 2002), which also denotes the radiation of the most diverse genus of angiosperm plants in the Atacama Desert, Nolana (Guerrero et al. 2013). The El Niño-Southern Oscillation (ENSO) is a recurring climate pattern on periods ranging from 3-7 years involving changes in the temperature of waters in the central and eastern tropical Pacific Ocean. The resulting oscillations of warming and cooling ocean water (ENSO cycle) directly affects rainfall and fog distribution in the tropics in general and in the Atacama Desert in particular.

\section{Conclusions and outlook}

Tillandsia landbeckii is a fascinating monospecific loma forming species in the Atacama Desert (Fig. 3d) starting its evolutionary history nearly 2 mya. Despite extreme environmental conditions in a hyperarid region and a presumably very narrow ecological niche we found evidence for ample gene flow among the various epiarenic and loma forming species including T. landbeckii and also ongoing hybrid speciation processes. There is some evidence that these processes might be triggered by major environmental change and significant distribution range shifts (T. marconae), but we are actually lacking detailed knowledge to understand the spatio-temporal dynamics behind. We aim in our future studies to compare phylogeographic and temporal evolutionary patterns among species to evaluate in some more detail potential drivers of speciation processes in epiarenic and loma forming Tillandsia species growing at the dry limits since latest from the Early Miocene onward.

\section{Information on Electronic Supplementary Mate- rial}

Online Resource 1. Accession data.

Online Resource 2. Primer design and amplification details for bridging contigs.

Online Resource 3. Summary of sequencing and assembly statistics. Online Resource 3. Barcode phylogeny.

Supplementary Information The online version contains supplementary material available at https://doi.org/10.1007/s00606-021-01760-5.

Acknowledgements We thank Peter Sack and Anna Loreth (Heidelberg) for technical support in the lab. We also acknowledge support from David Ibbersen heading Heidelberg Deep Sequencing Core Facility.

Author contribution M.A.K. conceived the project and the experiments. J.M., C.K. and M.A.K. conducted the experiment(s), J.M., C.K. and M.A.K. analyzed the results. M.A.K., C.K. and J.M. drafted the manuscript. All authors contributed to the final manuscript draft.

Funding Open Access funding enabled and organized by Projekt DEAL. This study was partly supported by the German Research Foundation (DFG) to M.A.K. and D.Q. within the CRC 1211 (http:// sfb1211.uni-koeln.de).

Data availability The datasets generated and analyzed during the current study are available from the corresponding author on reasonable request and have been deposited with DRYAD (https://doi.org/10.5061/ dryad.kh189324d). Accession data, barcode phylogeny, suppl. Material and Methods, and sequence statistics are presented with Online Resources 1-4.

\section{Compliance with ethical standards}

Conflict of interest The authors declare that they do have no conflict of interest.

Open Access This article is licensed under a Creative Commons Attribution 4.0 International License, which permits use, sharing, adaptation, distribution and reproduction in any medium or format, as long as you give appropriate credit to the original author(s) and the source, provide a link to the Creative Commons licence, and indicate if changes were made. The images or other third party material in this article are included in the article's Creative Commons licence, unless indicated otherwise in a credit line to the material. If material is not included in the article's Creative Commons licence and your intended use is not permitted by statutory regulation or exceeds the permitted use, you will need to obtain permission directly from the copyright holder. To view a copy of this licence, visit http://creativecommons.org/licenses/by/4.0/.

\section{References}

Alpers CN, Brimhall GH (1988) Middle Miocene climatic change in the Atacama Desert, northern Chile: evidence from supergene 
mineralization at La Escondida. Bull Geol Soc Amer 100:16401656. https://doi.org/10.1130/0016-7606(1988)100\%3c1640: MMCCIT\%3e2.3.CO;2

Aponte H, Flores J (2013) Density and spatial distribution of Tillandsia latifolia on the Tillandsial lomas of Piedra Campana (Lima, Perú). Ecol Aplicada 12:35-43

Barfuss MH, Samuel R, Till W, Stuessy TF (2005) Phylogenetic relationships in subfamily Tillandsioideae (Bromeliaceae) based on DNA sequence data from seven plastid regions. Amer J Bot 92:337-351. https://doi.org/10.3732/ajb.92.2.337

Barfuss MH, Till W, Leme EMC, Pinzón JP, Manzanares JM, Halbritter H, Samuel R, Brown GK (2016) Taxonomic revision of Bromeliaceae subfam. Tillandsioideae based on a multi-locus DNA sequence phylogeny and morphology. Phytotaxa 279:1-97. https:// doi.org/10.5962/bhl.title.78580

Bolger AM, Lohse M, Usadel B (2014) Trimmomatic: a flexible trimmer for Illumina sequence data. Bioinformatics 30:2114-2120. https://doi.org/10.1093/bioinformatics/btu170

Bouckaert R, Heled J, Kühnert D, Vaughan T, Wu CH, Xie D, Suchard MA, Rambaut A, Drummond AJ (2014) BEAST 2: a software platform for Bayesian evolutionary analysis. PLoS Comput Biol 10:e1003537. https://doi.org/10.1371/journal.pcbi.1003537

Bratzel F, Heller S, Cyrannek N, Paule J, Leme EMC, Loreth A, Nowotny A, Kiefer M, Till W, Barfuss MH, Lexer C, Koch MA, Zizka G (2020) The low-copy nuclear gene Agtl as a novel DNA barcoding marker for Bromeliaceae. BMC Pl Biol 20:1-11. https://doi. org/10.1186/s12870-020-2326-5

Brown GK, Gilmartin AJ (1989) Chromosome numbers in Bromeliaceae. Amer J Bot 76:657-665. https://doi.org/10.1002/j.15372197.1989.tb11361.x

Bull AT, Andrews BA, Dorador C, Goodfellow M (2018) Introducing the Atacama Desert. Antonie Van Leeuwenhoek 111:1269-1272. https://doi.org/10.1007/s10482-018-1100-2

Cereceda P, Pinto R, Larrain H, Osses P, Farías M (2004) Geographical description of three fog ecosystems in the Atacama coastal desert of Chile. In: Third International Conference on Fog, Fog Collection and Dew. Ciudad del Cabo, Cape Town

Contreras S, Lange CB, Pantoja S, Lavik G, Rincón-Martínez D, Kuypers MM (2010) A rainy northern Atacama Desert during the last interglacial. Geophys Res Lett 37:L23612. https://doi.org/ 10.1029/2010GL045728

Cotias de Oliveira ALP, Assis JGA, Bellintani MC, Andrade JCS, Guedes MLS (2000) Chromosome numbers in Bromeliaceae. Genet Molec Biol 23:173-177. https://doi.org/10.1590/S141547572000000100032

Doležel J, Bartoš J (2005) Plant DNA flow cytometry and estimation of nuclear genome size. Ann Bot 95:99-110. https://doi.org/10. 1093/aob/mci005

Doležel J, Binarová P, Lucretti S (1989) Analysis of nuclear DNA content in plant cells by flow cytometry. Biol Pl 31:113-120

Doležel J, Greilhuber J, Suda J (2007) Estimation of nuclear DNA content in plants using flow cytometry. Nat Protoc 2:2233. https:// doi.org/10.1038/nprot.2007.310

Doležel J, Sgorbati S, Lucretti S (1992) Comparison of three DNA fluorochromes for flow cytometric estimation of nuclear DNA content in plants. Physiol P1 85:625-631. https://doi.org/10. 1111/j.1399-3054.1992.tb04764.x

Donadío S, Pozner R, Giussani LM (2015) Phylogenetic relationships within Tillandsia subgenus Diaphoranthema (Bromeliaceae, Tillandsioideae) based on a comprehensive morphological dataset. Pl Syst Evol 301:387-410. https://doi.org/10.1007/ s00606-014-1081-1

Gilmartin AJ (1983) Evolution of mesic and xeric habits in Tillandsia and Vriesea (Bromeliaceae). Syst Bot 8:233-242. https://doi.org/ $10.2307 / 2418477$
Gitzendanner MA, Soltis PS, Yi T-S, Li D-Z, Soltis DE (2018) Plastome phylogenetics: 30 years of inferences into plant evolution. In: Advances in botanical research, vol. 85. Elsevier, London, pp 293-313. https://doi.org/10.1016/bs.abr.2017.11.016

Givnish TJ, Barfuss MH, Van Ee B, Riina R, Schulte K, Horres R, Gonsiska PA, Jabaily RS, Crayn DM, Smith JAC (2011) Phylogeny, adaptive radiation, and historical biogeography in Bromeliaceae: insights from an eight-locus plastid phylogeny. Amer J Bot 98:872-895. https://doi.org/10.3732/ajb.1000059

Gomes-da-Silva J, Costa A (2013) An updated overview of taxonomy and phylogenetic history of Tillandsioideae genera (Bromeliaceae: Poales). Global J Bot Sci 1:1-8

Granados Mendoza C, Granados-Aguilar X, Donadío S, Salazar GA, Flores-Cruz M, Hágsater E, Starr JR, Ibarra-Manríquez G, Fragoso-Martínez I, Magallón S (2017) Geographic structure in two highly diverse lineages of Tillandsia (Bromeliaceae). Botany 95:641-651. https://doi.org/10.1139/cjb-2016-0250

Guerrero PC, Rosas M, Arroyo MT, Wiens JJ (2013) Evolutionary lag times and recent origin of the biota of an ancient desert (AtacamaSechura). Proc Natl Acad Sci USA110:11469-11474. https://doi. org/10.1073/pnas.1308721110

Hartley AJ, Chong G (2002) Late Pliocene age for the Atacama Desert: implications for the desertification of western South America. Geology 30:43-46. https://doi.org/10.1130/00917613(2002)030\%3c0043:LPAFTA\%3e2.0.CO;2

Hartley AJ, Chong G, Houston J, Mather AE (2005) 150 million years of climatic stability: evidence from the Atacama Desert, northern Chile. J Geol Soc 162:421-424. https://doi.org/10. 1144/0016-764904-071

Hermida-Carrera C, Fares MA, Font-Carrascosa M, Kapralov MV, Koch MA, Mir A, Molins A, Ribas-Carbó M, Rocha J, Galmés J (2020) Exploring molecular evolution of Rubisco in C 3 and CAM Orchidaceae and Bromeliaceae. BMC Evol Biol 20:11. https://doi.org/10.1186/s12862-019-1551-8

Hesse R (2012) Spatial distribution of and topographic controls on Tillandsia fog vegetation in coastal southern Peru: Remote sensing and modelling. J Arid Environm 78:33-40. https://doi.org/ 10.1016/j.jaridenv.2011.11.006

Hesse R (2014) Three-dimensional vegetation structure of Tillandsia latifolia on a coppice dune. J Arid Environm 109:23-30. https:// doi.org/10.1016/j.jaridenv.2014.05.001

Hohmann N, Koch MA (2017) An Arabidopsis introgression zone studied at high spatio-temporal resolution: interglacial and multiple genetic contact exemplified using whole nuclear and plastid genomes. BMC Genom 18:1-18. https://doi.org/10.1186/ s12864-017-4220-6

Hohmann N, Wolf EM, Rigault P, Zhou W, Kiefer M, Zhao Y, Fu C-X, Koch MA (2018) Ginkgo biloba's footprint of dynamic Pleistocene history dates back only 390,000 years ago. BMC Genom 19:1-16. https://doi.org/10.1186/s12864-018-4673-2

Houston J, Hartley AJ (2003) The central Andean west-slope rainshadow and its potential contribution to the origin of hyperaridity in the Atacama Desert. Int J Climatol 23:1453-1464. https://doi.org/10.1002/joc.938

Katoh K, Misawa K, Ki K, Miyata T (2002) MAFFT: a novel method for rapid multiple sequence alignment based on fast Fourier transform. Nucl Acids Res 30:3059-3066. https://doi.org/10. 1093/nar/gkf436

Koch MA, Kleinpeter D, Auer E, Siegmund A, del Rio C, Osses P, García J-L, Marzol MV, Zizka G, Kiefer C (2019) Living at the dry limits: ecological genetics of Tillandsia landbeckii lomas in the Chilean Atacama Desert. P1 Syst Evol 305:1041-1053. https://doi.org/10.1007/s00606-019-01623-0

Koch MA, Schröder CN, Kiefer M, Sack P (2013) A treasure trove of plant biodiversity from the 20th century: the Werner Rauh Heritage Project at Heidelberg Botanical Garden and 
Herbarium. Pl Syst Evol 299:1793-1800. https://doi.org/10. 1007/s00606-013-0835-5

Koch MA, Stock C, Kleinpeter D, Del Rio C, Osses P, Merklinger FF, Quandt D, Siegmund A (2020) Vegetation growth and landscape genetics of Tillandsia lomas at their drylimits in the Atacama Desert show fine-scale response to environmental parameters. Ecol Evol 10:13260-13274. https://doi.org/10. 1002/ece3.6924

Kozlov AM, Darriba D, Flouri T, Morel B, Stamatakis A (2019) RAxML-NG: a fast, scalable and user-friendly tool for maximum likelihood phylogenetic inference. Bioinformatics 35:4453-4455. https://doi.org/10.1093/bioinformatics/btz305

Lanfear R, Frandsen PB, Wright AM, Senfeld T, Calcott B (2017) PartitionFinder 2: new methods for selecting partitioned models of evolution for molecular and morphological phylogenetic analyses. Molec Biol Evol 34:772-773. https://doi.org/10.1093/ molbev/msw260

Lazo Ramos RS (2011) Valoración biológica, física y geográfica de la hierba Siempre Viva Tillandsia werdermannii para su conservación en la Región Tacna, 2010. MSc Thesis, Universidad Nacional Jorge Basadre Grohmann, Tacna

Leme EMC, Halbritter H, Barfuss MHJ (2017) Waltillia, a new monotypic genus in Tillandsioideae (Bromeliaceae) arises from a rediscovered, allegedly extinct species from Brazil. Phytotaxa 299:1-35. https://doi.org/10.11646/Phytotaxa.299.1.1

Li H (2013) Aligning sequenc reads, clone sequences and assembly contigs with BWA-MEM. figshare. https://doi.org/10.6084/M9. FIGSHARE.963153.V1

Li H, Handsaker B, Wysoker A, Fennell T, Ruan J, Homer N, Marth G, Abecasis G, Durbin R (2009) 1000 Genome Project Data Processing Subgroup. 2009. The Sequence Alignment/Map format and SAMtools. Bioinformatics 25:2078-2079. https://doi.org/10.1093/ bioinformatics/btp352

Liu J, Niu Y-F, Liu S-H, Ni S-B (2016) The complete pineapple (Ananas comosus; Bromeliaceae) varieties F153 chloroplast genome sequence. Mitochondrial DNA B 1:390-391. https://doi. org/10.1080/23802359.2016.1174084

McKenna A, Hanna M, Banks E, Sivachenko A, Cibulskis K, Kernytsky A, Garimella K, Altshuler D, Gabriel S, Daly M (2010) The Genome Analysis Toolkit: a MapReduce framework for analyzing next-generation DNA sequencing data. Genome Res 20:12971303. https://doi.org/10.1101/gr.107524.110

Nashima K, Terakami S, Nishitani C, Kunihisa M, Shoda M, Takeuchi M, Urasaki N, Tarora K, Yamamoto T, Katayama H (2015) Complete chloroplast genome sequence of pineapple (Ananas comosus). Tree Genet Genomes 11:60. https://doi.org/10.1007/ s11295-015-0892-8

Paule J, Heller S, Maciel JR, Monteiro RF, Leme EMC, Zizka G (2020a) Early diverging and core Bromelioideae (Bromeliaceae) reveal contrasting patterns of genome size evolution and polyploidy. Frontiers Pl Sci 11:1295. https://doi.org/10.3389/fpls. 2020.01295

Paule J, Schmickl R, Fér T, Matuszak-Renger S, Halbritter H, Zizka G (2020b) Phylogenomic insights into the Fascicularia-Ochagavia group (Bromelioideae, Bromeliaceae). Bot J Linn Soc 192:642655. https://doi.org/10.1093/botlinnean/boz085

Pinto R, Barria I, Marquet PA (2006) Geographical distribution of Tillandsia lomas in the Atacama Desert, northern Chile. J Arid Environm 65:543-552. https://doi.org/10.1016/j.jaridenv.2005. 08.015

Poczai P, Hyvönen J (2017) The complete chloroplast genome sequence of the CAM epiphyte Spanish moss (Tillandsia usneoides, Bromeliaceae) and its comparative analysis. PLoS ONE 12:e0187199. https://doi.org/10.1371/journal.pone.0187199

Quinlan AR, Hall IM (2010) BEDTools: a flexible suite of utilities for comparing genomic features. Bioinformatics 26:841-842. https:// doi.org/10.1093/bioinformatics/btq033

Rambaut A, Drummond A (2012) FigTree: tree figure drawing tool, v1. 4.2. Institute of Evolutionary Biology, University of Edinburgh, Edinburgh

Rambaut A, Drummond AJ, Xie D, Baele G, Suchard MA (2018) Posterior summarization in Bayesian phylogenetics using Tracer 1.7. Syst Biol 67:901-904. https://doi.org/10.1093/sysbio/syy032

Rauh W (1985) The Peruvian-Chilean deserts. In: Goodall DW, NoyMeir I, Evenari M, Ecosystems of the world 12/A, Hot deserts and arid shrublands. Elsevier, Amsterdam, Oxford, New York, pp 239-267

Redwan RM, Saidin A, Kumar SV (2015) Complete chloroplast genome sequence of MD-2 pineapple and its comparative analysis among nine other plants from the subclass Commelinidae. BMC Pl Biol 15:196. https://doi.org/10.1186/s12870-015-0587-1

Ritter B, Binnie SA, Stuart FM, Wennrich V, Dunai TJ (2018) Evidence for multiple Plio-Pleistocene lake episodes in the hyperarid Atacama Desert. Quatern Geochronol 44:1-12. https://doi.org/10. 1016/j.quageo.2017.11.002

Rundel P, Villagra P, Dillon M, Roig-Juñent S, Debandi G (2007) Arid and semi-arid ecosystems. In: Veblen TT, Young KR, Orme AR (eds) The physical geography of South America. Oxford University Press, Oxford, pp 158-183

Rundel PW, Dillon MO (1998) Ecological patterns in the Bromeliaceae of the lomas formations of Coastal Chile and Peru. P1 Syst Evol 212:261-278. https://doi.org/10.1007/BF01089742

Rundel PW, Dillon MO, Palma B, Mooney HA, Gulmon S, Ehleringer J (1991) The phytogeography and ecology of the coastal Atacama and Peruvian deserts. Aliso J Syst Evolut Bot 13:1-49

Rundel PW, Palma B, Dillon M, Sharifi MR, Nilsen E, Boonpragob K (1997) Tillandsia landbeckii in the coastal Atacama Desert of northern Chile. Revista Chilena Hist Nat 70:341-349

Schulz N, Aceituno P, Richter M (2011) Phytogeographic divisions, climate change and plant dieback along the coastal desert of northern Chile. Erdkunde 65:169-187

Schulz N, Boisier J, Aceituno P (2012) Climate change along the arid coast of northern Chile. Int J Climatol 32:1803-1814. https://doi. org/10.1002/joc. 2395

Smith LB, Downs RJ (1977) Tillandsioideae (Bromeliaceae). Fl Neotrop Monogr 14:663-1492

Till W (1992) Systematics and evolution of the tropical-subtropical Tillandsia subgenus Diaphoranthema (Bromeliaceae). Selbyana 13:88-94

Wick RR, Judd LM, Gorrie CL, Holt KE (2017) Unicycler: resolving bacterial genome assemblies from short and long sequencing reads. PLoS Comput Biol 13:e1005595. https://doi.org/10.1371/ journal.pcbi.1005595

Zizka G, Munoz-Schick M (1993) Tillandsia marconae Till and Vitek, a bromeliad species new to Chile. Bol Mus Nac His Nat Santiago de Chile 44:11-17

Zizka G, Schmidt M, Schulte K, Novoa P, Pinto R, König K (2009) Chilean Bromeliaceae: diversity, distribution and evaluation of conservation status. Biodivers Conservation 18:2449-2471. https://doi.org/10.1007/s10531-009-9601-y

Publisher's Note Springer Nature remains neutral with regard to jurisdictional claims in published maps and institutional affiliations. 